\title{
Female Employees' Work Family Conflict and Job Satisfaction in Hospitality
}

\author{
Zhou Jin Quan', He Wen Jin ${ }^{2}$ \\ ${ }^{1}$ Tourism College, Hainan University Haikou, HaiNan Province, China \\ ${ }^{2}$ Electrical and Mechanical Engineering College, Hainan University Haikou, HaiNan Province, China \\ zjqzhfhwj@163.com, hewj8001@sina.com
}

\begin{abstract}
Along with tourism industry rapid development, more and more female employees have been working in this field since Hainan to be build to an international tourism destination. And as the tourism industry rapidly development and hospitality need more labor to fit this trend, more local female employees are currently working related to the hospitality industry. However, the special job characteristics of the hotel such as the working environment, work shift and psychological pressure, female employees will have a big challenge in job satisfaction facing the conflict between work and family. In this paper, we will investigate these relations among work-family conflict, job satisfaction and turn over of female hotel employees in Haikou city, focusing on the effects of job satisfaction and job turn over under the organizational support based on the role perception of their job. The results of this research provide corresponding sustainable development policies for the local Government, hotel enterprises and other related organizations about how to deduce working pressure, conflict level of work-family and job turn-over for female hotel employees.
\end{abstract}

Index Terms - Work-family Conflict, Job Satisfaction, Female Employees, and Hospitality.

\section{Introduction}

The hospitality industry which is a highly profitable industry can provide a higher salary to receive human resources, and the number of hotels is getting more everywhere in recent years in Haikou city. Haikou's census were stated in 3 quarter 2013 for hospitality human resource requirements that the vacancy of hotel is 2,229 compare last year 1458 , and the employee turnover rate is $6.5 \%$ and vacancy rate is $3.4 \%$ compared with last year fell $0.7 \%$ and $1.0 \%$ respectively. Indicators fall reflects that human resources demand deduced in the hospitality industry.

The employees in hotel need more irregular round work 24 hours a day compared with required general job requirement. More serious problems of job stress problem related to communication conflict with the customer caused by the work of day and night upside down and the staff more frequent interaction under hotel work conditions, such as noise, second-hand smoke and irregular shifts (Breen and Hing, 2012). The employees who have to keep jobs to feed their family and the family responsibility need to endure the heavy work stress compared with other industries, which derived various social problems, work stress, family problems, emotional distress, etc.

Working parents' family should take the role of workers in the fields of work and family, where they not only play the role of the family, but also the role of taking care of their children and parents (Zhang Huifen, Guo Miaoxue, 1998). However, in the case of limited time and energy, balance of work and family in every employee's life is a big problem focusing on how to use limited resources to achieve a win-win situation.

\section{Literature Review}

\section{A. Work Family Conflict}

Work family conflict refers to the conflict between two areas of the work and family life. Many scholars have agreed that this kind of conflict is among diversified roles as argued by Kahn (1964) that work family conflict is a result of unbalance between requirements of work role and family role conflict that is a type of role conflict. Greenhaus and Beutell's (1985) synthesis predecessors proposed comprehensively, further arguing that the work family conflict is a kind of special form of role conflict between work and family roles in the field of two stresses in some ways, when this phenomenon occurs, individual role requirements work (family) role for participation in family (work) become more difficult. When the two roles appear to be incompatible contradictions, conflict interaction of the roles will produce. Namely, it is hard for individuals to family responsibility because work tasks or work needs, the family burden and affect the completion of work inverse (Duxbury \& Higgins, 1991).

In early studies, scholars focused on the research of one direction conflict measure work interfering family. Then scholars began to realize the important of research on the two direction conflict. Fron, et al (1992) indicated that the work family conflict can be divided into two kinds of conflict, including the work interference with family (WIF) and the family interference with work (FIW), which are related to each other but different concepts with different causes and consequences. Recent studies found that there is a positive interaction relationship between two kinds of conflict. If personal work problems interfere with family responsibilities which are happening, which will have in turn family interferes with the work. When the family problems interfere with the job, uncompleted work will affect their family life.

Netemeyer (1996) argued the work family conflict come from the pressure of working where work needs and personal investment of time, the stress is hindered the performance of individual responsibilities in the family, which can lead to conflict. When the pressure from work and family is in some ways of the incompatible contradictions, therefore this kind of 
role conflict interaction can be produced.

In addition to the bi-directional nature of conflict, researchers have considered the different forms of work-family conflict (Greenhaus and Beutell, 1985). The three different forms of work-family conflict have been defined as time-based conflict, strain-based conflict, and behaviour-based conflict. According to Greenhaus and Beutell (1985), time-based conflict occurs when time contributes to one role inhibiting from participating in another role, strained-based conflict states that a strained experience in one role intrudes into and intervenes with participation in another role, and behaviourbased conflict happens when certain behaviours required in one role are incompatible with expected behaviours in another role.

Since work-family conflict is recognized bi-directionally, Gutek, et al (1991) further argued that each of these three forms of work-family conflict should have two directions as well and formed six dimensions of work-family conflict

The aforementioned six dimensions of conflict are objective existence caused by objective factors. As for the individual cognitive conflict, however, these factors do not necessarily result in personal perception of the conflict. Therefore, the perception of work family conflict is divergent because of the differences of personal individual attributes, and psychological factors or background.

\section{B. Work Family Conflict and the Premise Variables}

Eby (2005) revealed that gender differences and gender role is vital to fully understand the work-family conflict. In traditional concept, men invested more in our work, and women tend to be positioned as the role of wife and mother. As a result, male will experience more work-family conflict, and female experience more of family-work conflict (Cinamon, 2002). According to Spector (1997), "role conflict exists when people experience incompatible demands about their functions and responsibilities (p. 39)." Role conflict and role ambiguity are the two major components of job-related role stresses. If a woman is engaged in the work, time and energy to take care of the children and family will be dispersed, which is bound to feel a higher level of work family conflict (Dalen, 2006). However, several studies showed that work family conflict, gender differences are not significant (Izraeli, 1993). Carlson (2002) also found that women experience more work-family conflict and pressure of the family-based work conflict, and time conflict of family-work is not significant in gender differences. As defined by Spector (1997), "role ambiguity is the degree what the employee's functions and responsibilities are (p. 39)." According to classical theory, every position in a structured organization should have a specified set of tasks or position responsibility, role ambiguity is reflected into the degree of employees' uncertainty regarding the appropriate actions in performing job functions (Miles, 1976).

\section{Work Family Conflict and Result Variables \\ 1) Job Satisfaction}

The concept of job satisfaction was originally from Hop pock's "job satisfaction" in 1935. Job satisfaction is a worker's attitude or emotional reaction on the psychological and physical aspects of the work itself and working environment factors, which can also be called the worker's feeling and a kind of subjective reaction to his work situation.

Related studies of job satisfaction have been more active based on the theoretical framework and differentia of the research scope and focus, which have different definitions made below.

Job satisfaction is a kind of emotional experience and feeling which can not be measured directly. Indirect method of measuring job satisfaction includes staff observation, interview and questionnaire survey. Because the observation and interview is time-consuming, some researchers adopt questionnaire investigation measure. Da llen et al (2002) studied the aforementioned two kinds of methods of satisfaction measurement and work family conflict, the results interpreted significantly in relation to work-family conflict and two types of job satisfaction, but the relationship between the factors and work combined evaluation method is better than the single evaluation method. Liu Luo et al. (2005) distributed questionnaires to 220 full-time workers in Taiwan, the research results showed that work-family conflict and job satisfaction have a negative impact; work-family conflict can predict job satisfaction. Lai Jiamin (2011) built a research object using the questionnaires to study 153 people, found a negative impact between work-family conflict and job satisfaction under the work time affect.

H: 1 Work - family conflict has a significant correlation with female hospitality employee job satisfaction

$H$ : 1-1 Work interference the family has a significant negative correlation with female hospitality employee job satisfaction

H: 1-2 Family interference with work has a significant negative correlation with female hospitality employee job satisfaction

\section{2) Intention to Leave}

Fishbein and Ajzen (1975) proposed a turnover model based on the theory of planned behaviour that an individual may have is related to the person's attitude, and would finally lead to a specific behaviour. Ere (2001) agreed that the Fishbein and Ajzen attitude model was based on the premise that 'employees' behaviours could be influenced by the extent to which other people expected them to behave in a certain manner, and is further reinforced by personal motivation on the person's part to comply with such expectations. Richer, Blanchard and Vallerand's (2002) study of motivational theory confirmed that turnover intentions have been considered as actual turnover behaviour over time. Empirical evidence was also provided by the Saratoga Institute that compared to an employee's initial dissatisfaction with responses to a post-exit survey (Branham, 2005).

Hammer et al. (2003) showed where withdrawal behaviour was studied due to work-to-family conflict and family-to-work conflict. This study confirmed a significant 
individual level and crossover effects for both types of conflicts and withdrawal behaviours. The results of this study can be used to provide assistance in examining the cross effects of work-family conflict as a stressor in dual earner couples.

A lot of studies have reported the effect of non-work factors such as job stress and exhaustion makes workers to shift from the organization and such roles that create job stress, work-family clashes and lead the employee to leave the organization. The personal attributes of the employee, the level of support employees received at job, the industry norms and the management of these components in the workplace will pass its impact on work-family conflicts that can effect job contentment and organizational commitment, and ultimately lead to employee turnover (Rowley \& Purcell, 2001; Mulvaney et al., 2006; Namasivayam \& Zhao, 2007). Therefore, work-life balance is necessary to retain employees. Otherwise, an employer should implement such changes in his organization which fulfil the basic policies \& requirements of his employees so that turnover intentions ratio can be decreased easily. Work-Life harmony is a critical business strategy to reduce employee turnover, and to improve overall firm performance (Soon et al., 2005). The more the physical/psychological symptoms, and turnover intention, the greater the work-family imbalance reported among participants (Ling \& Phillips, 2006).

H: 2 Work and Family Conflict has a significant correlation with female hospitality employee Retention

$H$ : 2-1 Work Interference the family has a significant negative correlation female hospitality employee Retention

$H$ : 2-2 family Interference the work has a significant negative correlation female hospitality employee Retention

\section{3) Job Satisfaction and Intention to Leave}

Job dissatisfaction is a primary predictor of nurses' intention to leave (quit their current job) (Shields \& Ward, 2001; Tzeng, 2002). A study conducted in the United States presented evidence, showing that dissatisfied nurses were $65 \%$ more likely to have intention to leave compared to their satisfied counterparts (Shields \& Ward, 2001). Other predictors of intention to leave vary from low salaries and fringe benefits, inflexible work schedule (Coomber \& Barriball, 2007; Hayes et al, 2006), career advancement prospects (Tzeng, 2002, Rambur et al., 2003), in addition to poor management and job stress (Rambur et al., 2003).

H: 3 Job satisfactions have a significant correlation with employee Retention for female hospitality employee

\section{Hypothesis}

H: 1 Work - family conflict has a significant correlation with female hospitality employee job satisfaction

$H$ : 1-1 Work Interference the family has a significant negative correlation with female hospitality employee job satisfaction

H: 1-2 Family Interference with work has a significant negative correlation with female hospitality employee job satisfaction

H: 2 Work and Family Conflict has a significant correlation with female hospitality employee Retention

H: 2-1 Work Interference the family has a significant negative correlation female hospitality employee Retention

H: 2-2 Work Interference the family has a significant negative correlation female hospitality employee Retention

H: 3 Job satisfactions have a significant correlation with employee Retention for female hospitality employee

\section{Research Methodology}

\section{A. Measuring Instrument}

The work-family conflict measure scale are designed according to Carlson et al.'s (2000) multidimensional scale which was applied, including three dimensions of work-family conflict (time conflict, stress conflict and behaviour conflict) developed by Greenhaus and Beutell (1985) and combined with Netemeyer's (1996) direction of work-family conflict questionnaire (including work-family conflict and family inferred work conflicts). The measurement scale included 6 dimensions, measure items were a total of 18 . Job satisfaction measure scale is designed based on the Hoppock (1935) and Boonzaier, et al (2001) job satisfaction scale, the scale contains 4 items. Leave retention measure scale is mainly developed by Camman et al. (1979), Price and Mueller (1981) turnover intention questionnaire, using the reverse questionnaire measure retention, including 3 items. All measure scale designed a total of 25 items measured using a five-point Likert scale.

\section{B. Sample}

In this paper, questionnaire focuses on investigating female employees in 18 hotels according to the previous analysis. The population used for study focused on the female employees in 18 hotels (include 5 5-star hotels, 6 4-star hotels and 7 3-star hotels) in Haikou city. 500 respondents were selected using simple random sampling technique. This study was based on primary data collection from the questionnaire which consisted of four major parts, containing 25 items. The first nine questions were used to measure variable "workfamily conflict", another nine questions were used to measure variable "family-work conflict", and the other six questions were used to measure variable "job satisfaction", and the last three questions were used to measure variable "employee retention'.5 point Likert scale was used to increase the response rate (from $1=$ strongly disagree to $5=$ strongly agree). Cranach's alpha was 7.5. Data for questions regarding age, marital, education, job, work years and revenue was recorded. 500 questionnaires were randomly distributed to employees of 18 hotels in Haikou city from June to August 2013, responses from 445 questionnaires were received, and the invalid questionnaires are 413 which response rate was $82.6 \%$. SPSS 20 is used to investigate the data with the help of descriptive and regression analysis.

In the study sample, for the marital status, single is $35.6 \%$, and married with children is about $48.2 \%$; For the age 
status, mainly distributed is the age of 25 to 35 years old is $35.4 \%$ and 35 to 45 years old is $32.0 \%$, the majority is the young adults; Working organization of the participants is 5 star hotel (26.1\%),4-star hotel(31.9\%) and 3-star hotel (42.1\%), there job is Registration(28.8\%), Housekeeping(30.6\%) and Food and beverage $(40.7 \%)$. As for the status of job seniority, the majority is $37.3 \%$ from 5 to 10 years, the $30.3 \%$ participants is under 3 years, $24.0 \%$ is from 3 to 5 years; $38.5 \%$ is from junior high school and $22.8 \%$ elementary school, high school is $24.9 \%$, a university degree is about $8.5 \%$.

\section{Discussion}

\section{A. Reliability and validity analysis}

In this paper, using the scale of the significance and KMO value of Bartlett spherical inspection (as shown in Table 4), respectively, the KMO value of the work-family conflict is 0.889 , and Bartlett spherical inspection is significant $(\mathrm{p}<$ 0.000 ). The KMO value of Family-work conflict is 0.896 , Bartlett spherical inspection is significant $(\mathrm{p}<0.000)$; job satisfaction of KMO value is 0.802 , and Bartlett spherical inspection is significant $(\mathrm{p}<0.000)$; Leave the retention of $\mathrm{KMO}$ value is 0.709 , Bartlett spherical inspection is significant $(\mathrm{p}<0.000)$.

Principal component analysis is use for factor extraction, and the rotation is the biggest variation method for analysis. Cumulative variance is used to explain variance is $60.29 \%$, $62.39 \%, 65.36 \%$ and $71.01 \%$ respectively, and it can be judged that latent variable has a better convergence.

The results of reliability test show that as for job satisfaction measurement, Cronbach's $\alpha$ value is 0.821, belonging to high reliability. Cronbach's $\alpha$ for other dimensions such as work-family conflict, family-work conflict and leave retention is $0.874,0.872$ and 0.792 respectively were higher than 0.700 . That is given to show the reliability of variables which can be used in the further research.

\section{B. Hypotheses Analysis}

TABLE I Hypothesis Testing

\begin{tabular}{|c|c|c|c|c|}
\hline Hypotheses & $\beta$ & $\mathrm{R}^{2}$ & $\mathrm{~F}$ & Result \\
\hline $\mathrm{H} 1$ & $-.220^{* * *}$ & 0.038 & 16.397 & acceptance \\
\hline $\mathrm{H} 1-1$ & $-.173^{* * *}$ & 0.036 & 15.313 & acceptance \\
\hline $\mathrm{H} 1-2$ & $-.168 * * *$ & 0.024 & 10.028 & acceptance \\
\hline $\mathrm{H} 2$ & $0.284 * * *$ & 0.081 & 36.083 & acceptance \\
\hline $\mathrm{H} 2-1$ & $-0.288^{* * *}$ & 0.068 & 29.887 & acceptance \\
\hline $\mathrm{H} 2-2$ & $-0.319^{* * *}$ & 0.058 & 25.388 & acceptance \\
\hline H3 & $0.897 * * *$ & 0.545 & 491.419 & acceptance \\
\hline$* \mathrm{p}<0.05, * * \mathrm{p}<0.01, * * * \mathrm{p}<0.001$. & \\
\hline
\end{tabular}

\section{Conclusions}

This study shows that the influence of work-family on job satisfaction has significant negative effects for female employees in hospitality industry. There might be some other factors (personality and work stress) which have more significant relationships with work-family conflict on job satisfaction negatively correlated significantly can predict job satisfaction. Working hours are not stability which can influence job satisfaction and intention to leave. In addition, our findings support the previous studies, stating that there is a positive relationship between job satisfaction and intention to leave.

\section{References}

[1] Boonzaier, B., Ficker, B. \& Rust, B. (2001). A review of research on the job characteristics model and the attendant job diagnostic survey. South African Journal of Business Management, 32(1), 11-34.

[2] Cammann, C., Fichman, M., Jenkins, D., \& Klesh, J. (1979). The Michigan organizational assessment questionnaire. Unpublished manuscript, University of Michigan, Ann Arbor.

[3] Carlson D. S., Kacmar, K. M., \& Williams, L. J. (2000). Construction and initial validation of a multidimensional measure of work-family conflict. Journal of Vocational Behavior, 56, 249-276.

[4] Duxbury, L. E., \& Higgins, C. A. (1991). Gender differences inworkfamily conflict. Journal of Applied Psychology, 76, 60-74.

[5] Greenhaus, J. H., \& Beutell, N. J. (1985). Sources of conflict between work and family roles. Academy of Management Review, 10, 76-88.

[6] Hammer, L. B., Bauer, T. N, \& Grandey, A. A. (2003). Work-family conflict and work-related withdrawal behaviors. Journal of Business and Psychology, 17(3), 419-436

[7] Hoppock, R. (1935). Job satisfaction. New York, NY: Harper and Brothers.

[8] Kim, J. L. S., \& Ling, C. S. (2001). Work-family conflict of women entrepreneurs in Singapore. Women in Management Review, 16(5), 204-221.

[9] Ling, S. O., \& Phillips, D.R. (2006). Research on family-friendly employment policies and practices (FEPPs) in Hong Kong. Commissioned by the Equal Opportunities Commission and the Women's Commission.

[10] Mulvaney, R., O’Neill, J., Cleverland, J., \& Crouter, A. (2006). A model of work-family dynamics of hotel managers. Annals of Tourism Research, 34(1), 66-87.

[11] Namasivayam, K., \& Zhao, X. (2007). "An investigation of the moderating effects of organizational commitment on the relationships between work-family conflict and job satisfaction among hospitality employees in India. Tourism Management, 28(5), 1212-1223.

[12] Netemeyer, R. G., Boles, J. S., \& McMurrian, R. (1996). Development and validation of workfamily conflict and family-work conflict scales. Journal of Applied Psychology, 81(4), 400-410.

[13] Nicole, E. A. (2003). "The difficulty of leaving work inside the prison walls: An explanatory analysis of female correlational officer identity". Presented at the annual meeting of the American Society of Criminology, Chicago, IL.

[14] Noor S. and Maad, N. (2008). "Examining the Relationship between Work Life Conflict, Stress and Turnover Intentions among Marketing Executives in Pakistan". International journal of Business and Management. 3(11), 43-56.

[15] Parasuraman S. \& Simmers C.A. (2001). "Type of Employment, WorkFamily Conflict and Well-Being: A Comparative Study". Journal of Organizational Behavior. 22 (5) 551-568.

[16] Price, J., \& Mueller, C. (1981). A causal model of turnover for nurses. Academy of Management Journal, 24(3), 543-565

[17] Richer, S. F., Blanchard, C., \& Vallerandi, R. J. (2002). A motivational model of work turnover. Journal of Applied Social Psychology, 32(10), 2089-2113.

[18] Soon, A., Quazi, H.A., Tay, C., \& Kelly, K. (2005). Studies on the impact of work-life initiatives on employee \& firm performance. Executive Report for Public release. 